\title{
Elevated Plasma Peptide YY in Human Neonates and Infants
}

\author{
T. E. ADRIAN, ${ }^{1}$ H. A. SMITH, S. A. CALVERT, A. AYNSLEY-GREEN, AND S. R. BLOOM \\ Department of Medicine, Roval Postgraduate Medical School, Hammersmith Hospital, London, Department of \\ Pediatrics, John Radcliffe Hospital, Oxford [S.A.C.], and Department of Child Health, University of Newcastle \\ Upon Tyne, Newcastle Upon Tyne, England [A.A-G.]
}

\begin{abstract}
Plasma concentrations of peptide YY (PYY) were measured in cord blood and at 6,12 , and 18 days of postnatal life in 24 healthy preterm neonates, from cord blood of eight full-term neonates, and from peripheral blood of 13 infants 9 months old. Concentrations were high in cord blood $(73 \pm 9 \mathrm{pmol} /$ liter versus adult fasting 10.4 $\pm 1.3, p<0.001)$ and rose postnatally in the premature infants to $399 \pm 48 \mathrm{pmol} / \mathrm{liter}$ at 6 days, $489 \pm 42$ at 12 days, and fell to $414 \pm 43$ at 18 days. Plasma PYY concentrations were much lower in infants 9 months old (32 $\pm 3 \mathrm{pmol} /$ liter), suggesting that the postnatal surge of plasma PYY is a feature of early adaptation to extrauterine life. Gel permeation chromatograms revealed that the major circulating form of PYY in the neonate eluted in a position identical to that of the pure 36 amino acid peptide. There was, however, evidence of two larger molecular forms that may be precursor molecules. Because PYY is a peptide that exhibits potent effects on gastrointestinal secretion and motility in humans, these observations suggest that this candidate gut hormone may be important in the adaptation to enteral nutrition in the neonate. (Pediatr Res 20: 1225-1227, 1986)
\end{abstract}

\section{Abbreviation}

PYY, peptide tyrosine tyrosine or peptide YY

PYY is a recently discovered candidate gut hormone that has a broad spectrum of biological actions (1-5). PYY is produced by endocrine cells in the distal bowel, and plasma concentrations rise in response to the ingestion of food $(3,6,7)$. Infusion studies in adult humans, at doses producing increments of plasma PYY concentrations within the physiological range, have revealed potent inhibitory effects on gastric secretion and emptying and also a delay of mouth-cecum transit $(8,9)$. Recently we observed that circulating PYY concentrations in young healthy pigs were greater than those of adult humans and rats $(6,10)$. Although this difference may have been due to species it raised the possibility that PYY plays a particular role in the developing animal (7). The aim of the present study was to measure plasma PYY concentrations at birth and in early life to evaluate whether this peptide could be important in the adaptation of the human neonate to extrauterine life.

Received February 2, 1986: accepted July 3. 1986

Correspondence S. R. Bloom. Department of Medicine, Royal Postgraduate Medical School. Second Floor Francis Fraser Labs. Hammersmith Hospital, Du Cane Road, London W12 OHS, United Kingdom.

${ }^{1}$ Current address Department of Surgery. Yale University School of Medicine, New Haven. CT.

\section{PATIENTS AND METHODS}

Healthy infants born before 34 wk gestation entered the study, which was approved by the hospital ethics committee. Informed parental consent was also obtained; 24 infants were studied. The mothers of 15 of these (birth weight $1620 \pm 67 \mathrm{~g}$, gestation $32 \pm$ $1 \mathrm{wk}$, mean $\pm \mathrm{SE}$ ) wanted to establish lactation, and their infants were fed only with regular boluses of breast milk by nasogastric feeding tube. The nine infants of mothers not wishing to breastfeed (birth weight $1564 \pm 117 \mathrm{~g}$, gestation $31 \pm 1 \mathrm{wk}$, mean \pm $\mathrm{SE})$ were given regular boluses of an adapted milk formula (Nenatal, Nutricia International BV) in daily volumes as recommended by the manufacturer. Both groups of infants tolerated their feeds well and gained weight as expected. None developed diarrhea or any other complication, and all were discharged within a month, once weight had reached $\sim 2000 \mathrm{~g}$.

Venous blood samples were drawn from the umbilical cord at birth and immediately before a feed at 6,12 , and 18 days of life when routine monitoring investigations were required. Cord plasma samples also were taken from eight normal infants after full-term deliveries. Fasting plasma samples were also taken from 13 infants aged $9 \pm 1$ months (mean \pm SE). A 1 -ml blood sample was placed into a chilled heparinized tube containing $1000 \mathrm{KIU}$ aprotinin (Trasylol, Bayer) before immediate centrifugation; the plasma was stored at $-20^{\circ} \mathrm{C}$ until assayed.

Plasma concentrations of PYY were measured using a specific and sensitive radioimmunoassay (6). The antisera showed no significant cross-reaction with neuropeptide $Y$ or pancreatic polypeptide. The assay was modified in that only $20 \mu \mathrm{l}$ plasma were assayed in duplicate for the neonatal samples because of the high concentrations encountered. Adult and cord blood samples were assayed at $200 \mu \mathrm{l}$ in duplicate by the routine procedure. The assay could therefore detect changes between adjacent samples of $20 \mathrm{pmol} /$ liter (neonates) and $2 \mathrm{pmol} / \mathrm{liter}$ (adults) with $95 \%$ confidence (6).

Plasma samples from each of the three infant groups. $(50 \mu \mathrm{l}$ from each neonate) were pooled for gel permeation chromatography. This was performed on a $100 \times 1.5 \mathrm{~cm}$ column of Sephadex G-50 superfine (Pharmacia), eluting with $60 \mathrm{mM}$ phosphate buffer ( $\mathrm{pH} 7.4$ ) with $10 \mathrm{mM}$ EDTA, $6 \mathrm{M}$ urea, and $50 \mu \mathrm{M}$ bovine albumin. The flow rate for the column was 10 $\mathrm{ml} / \mathrm{h}$, and 2-ml fractions were collected for subsequent radioimmunoassay.

Statistical analysis was performed using Student's $t$ test for unpaired data.

\section{RESULTS}

Mean umbilical venous plasma PYY concentrations in term and preterm infants were $112 \pm 18$ and $73 \pm 10 \mathrm{pmol} / \mathrm{liter}$ (mean $\pm \mathrm{SE}$ ), respectively, $p<0.05$. Fasting plasma PYY concentrations in 20 healthy adults $(10.4 \pm 1.3$ pmol/liter, mean \pm 
SE) were significantly lower than the cord levels in both term and preterm infants $(p<0.001)$. Plasma PYY concentrations rose dramatically after birth in breast milk and formula fed preterm babies, to a peak at 12 days (Fig. 1). There were no statistically significant differences in PYY levels between these two groups. In contrast plasma PYY concentrations in infants aged 9 months were $32 \pm 3 \mathrm{pmol} / \mathrm{l}$, which was much lower than in the cord blood and during the first 18 days of postnatal life but still higher than adult levels $(p<0.001)$.

Gel permeation chromatography of pooled plasma samples at 6,12 , and 18 days after birth revealed that approximately $60 \%$ of immunoreactive PYY eluted in an identical position to the pure 36 amino acid PYY standard (Kav 0.38) (Fig. 2). About 10 and $30 \%$ eluted in two earlier positions with Kav 0.16 and 0.30 , respectively. The relative proportions of these peaks appeared similar at the three ages.

\section{DISCUSSION}

Circulating concentrations of PYY in the early postnatal period in preterm infants increased dramatically and peaked within the first 2 wk postpartum. At their peak the plasma PYY concentrations were nearly 50 times higher than fasting levels in normal adults and 10 times higher even than the peak postprandial response seen after a massive 5000-cal meal in young adults (6). Chromatography of PYY immunoreactivity in neonates showed that most of it eluted in an identical position to the pure 36 amino acid hormonal peptide. Considerable quantities of two other earlier eluting peaks were also seen, however. These may represent precursor forms that have not undergone complete post translational enzymic processing. Such high molecular weight forms have been noted for several other peptide hormones $(11,12)$. These are particularly prevalent in the fetus and neonate, as may be expected due to immature cellular processes $(13,14)$. Indeed high molecular weight forms of PYY predominate in young healthy pigs, which had high plasma PYY concentrations like the human infants in this study (7).

High PYY concentrations occur in many pathological conditions, such as malabsorption due to sprue or chronic pancreatitis or dumping syndrome after gastric surgery and small bowel resection $(15-17)$. In all of these circumstances undigested nu-

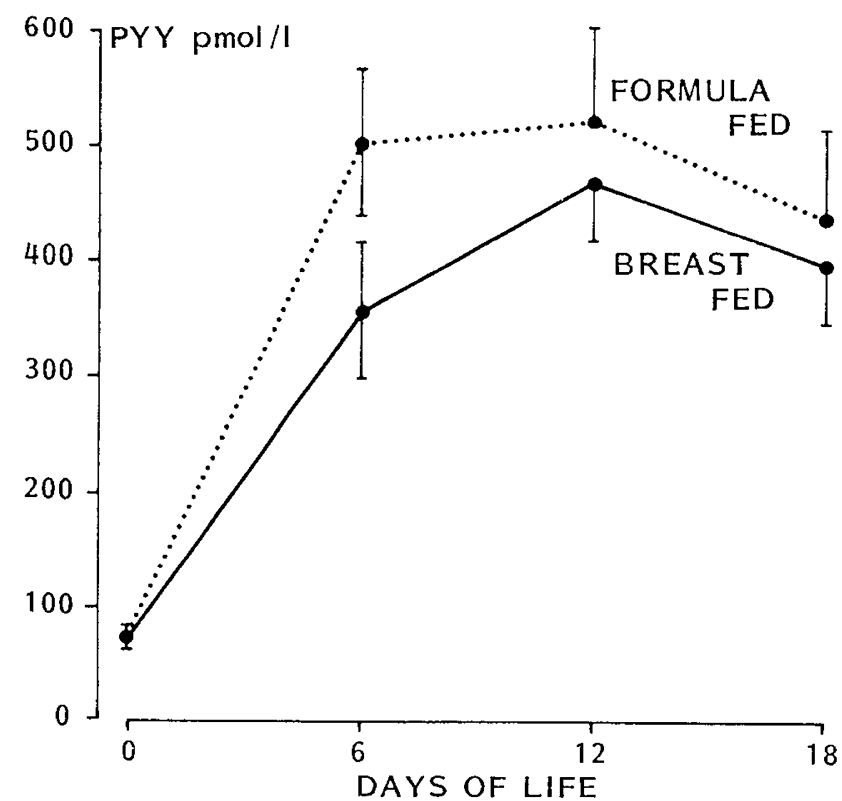

Fig. 1. PYY concentrations in umbilical venous plasma (day $0, n=$ 24) and prefeed plasma from preterm infants receiving either human milk $(n=15)$ or milk formula $(n=9)$ at 6,12 , and 18 days of postnatal life (mean \pm SE).

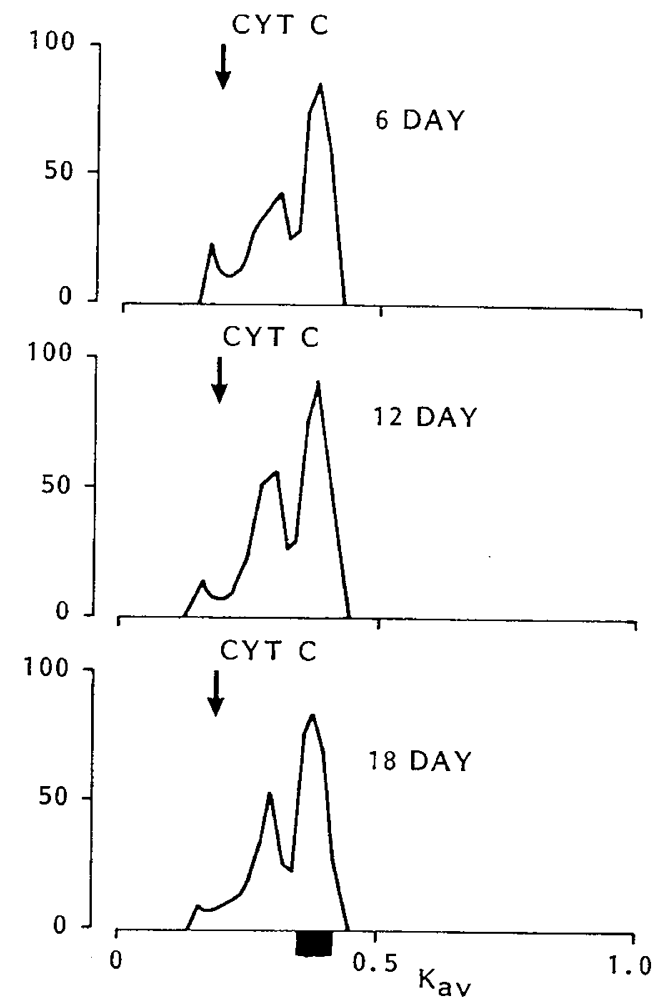

Fig. 2. PYY-like immunoreactivity in gel permeation chromatograms in pooled prefeed plasma from preterm infants at 6,12 , and 18 days after birth. Recoveries were greater than $90 \%$. Arrow, position of cytochrome c; block, synthetic porcine PYY.

trients pass down into the distal bowel where the release of PYY is presumably stimulated.

At birth intravenous nutrition via the placenta ceases, and the neonate must adapt to enteral feeding. By the age of $2 \mathrm{wk}$ a preterm neonate consumes a daily volume of milk that, on a proportionate body weight basis in the adult, would correspond to a fluid intake of more than 10 liter/day. Clearly, the periodic administration of these large volumes of milk to infants must necessitate changes in intestinal motility. Indeed there is evidence to suggest that gastric emptying and intestinal transit are rapid during the 1 st wk of life in both term and preterm neonates (18). The triggering mechanism for the changes that then occur is unknown, but it is very likely that circulating gastrointestinal hormones play a role (19). Indeed gastrointestinal hormones in the neonate are generally higher than in the adult (19).

When infused into humans at concentrations that produce plasma levels within the physiological range, PYY potently inhibits gastric acid secretion, slows gastric emptying, and increases the mouth to cecum transit time $(8,9)$. It is unknown how these actions could relate to the adaptation to enteral feeding in the neonate. The pattern of acid secretion during the first days of life is complex $(18,20-22)$. Acid secretion is detectable within minutes after birth, reaches a peak within the first day or two, and decreases thereafter for about a month (18, 20-22). Indeed one study showed that mean basal acid output was at its lowest on the tenth day of life, which is about the time when PYY levels are highest (22). Hypergastrinemia has been reported at this stage and is probably a physiologically important event because gastrin is trophic to the antral mucosa (22-24). High PYY levels may suppress the acid hypersecretion that would otherwise occur. The high PYY levels seen in infants could also be seen as an adaptive response to the rapid passage of nutrients through the stomach and small bowel of the infant. PYY reduces the rate of gastric emptying and slows the rate of small bowel transit, thereby allowing more time for absorption. It is presumed that a similar 
mechanism is involved in malabsorption where PYY levels are similarly increased (15).

Thus PYY, a hormonal peptide with powerful inhibitory effects on gastric secretion and gastrointestinal motility may be important in the adaptation of the neonate to enteral feeding.

\section{REFERENCES}

1. Tatemoto K. Mutt V 1980 Isolation of two novel candidate hormones using a chemical method for finding naturally occurring polypeptides. Nature 285:417-418

2. Tatomoto K 1982 Isolation and characterization of peptide YY (PYY), a candidate exocrine secretion. Proc Natl Acad Sci USA 79:2514-2518

3. Lundberg JM, Tatemoto K. Terenius L. Hellstrom PM, Mutt V, Hokfelt T. Hamberger B 1982 Localization of peptide YY (PYY) in gastrointestinal endocrine cells and effects on intestinal blood flow and motility. Proc Natl Acad Sci USA 79:447 1-4475

4. Suzuki J. Nakava M. Itoh Z. Tatemoto K. Mutt V 1983 Inhibiton of interdigestive contractile activity in the stomach by peptide $\mathrm{YY}$ in Haidenhain pouch dogs. Gastroenterology 85:114-121

5. Allen JM, Adrian TE. Tatemoto K. Polak JM, Hughes J. Bloom SR 1982 Two novel related peptides. neuropeptide $\mathrm{Y}$ (NPY) and peptide $\mathrm{YY}$ (PYY) inhibit the contraction of the electrically stimulated mouse vas deferens. Neuropeptides 3:71-75

6. Adrian TE. Ferri G-L. Bacarese-Hamilton AJ. Fuessl HS, Polak JM, Bloom SR 1985 Human distribution and release of a putative new gut hormone. peptide XY (PYY). Gastroenterol 89:1070-1077

7. Adrian TE, Bacarese-Hamilton AJ. Smith H, Chohan P, Manolas KJ. Bloom $\mathrm{Sr} 1986$ Distribution and postprandial release of porcine peptide YY (PYY). $\mathrm{J}$ Endocrinol (in press)

8. Adrian TE. Savage AP. Sagor GR. Allen JM. Bacarese-Hamilton AJ, Tatemoto K. Polak JM. Bloom SR 1985 Effect of peptide YY on gastric, pancreatic and biliary function in humans. Gastroenterology 89:494-499

9. Savage AP. Adrian TE. Carolan G. Chatterjee VK, Polak JM, Bloom SR Effects of peptide $\mathrm{YY}$ (PYY) on mouth-caecum and gastric emptying. Gu (in press)

10. Savage AP, Gornacz GE, Adrian TE. Ghatei MA. Goodlad RA. Wright NA. Bloom SR 1985 Is raised plasma peptide $Y Y$ after intestinal resection in the rat responsible for the trophic response? Gut 26:1353-1358

11. Steiner DG, Duguid JR, Patzelt C, Chan SJ, Qunn P, Labrecque A, Hastings R 1979 New aspects of insulin biosynthesis In: Baba S, Kaneko T, Yanaihara $\mathrm{N}$ (eds) Proinsulin, Insulin, C-Peptide. Excerpta Medica, Amsterdam, pp 919

12. Dockray GJ 1981 Multiple molecular forms of hormones: Significance and methods of study. In: Bloom SR, Polak JM (eds) Gut Hormones. Churchill Livingstone, London, pp 43-48

13. Bryant MG, Buchan AMJ, Gregor M, Ghatei MA, Polak JM, Bloom SR 1982 Development of intestinal regulatory peptides in the human fetus. Gastroenterology 83:47-54

14. Anderson BN Abramovitch D, Brand SJ, Petersen B, Rehfeld JF 1985 Complete sulphation of jejunal gastrin in the human foetus. Regul Pept 10:329338

15. Adrian TE, Savage AP, Bacarese-Hamilton AJ, Wolfe K, Besterman HS, Bloom SR 1986 Peptide YY abnormalities in gastrointestinal diseases. Gastroenterology 90:379-384

16. Adrian TE, Long RG, Fuessl HS, Bloom SR 1985 Plasma peptide YY (PYY) in dumping syndrome. Dig Dis Sci 30:1145-1148

17. Adrian TE, Savage AP, Fuessl HS, Wolfe K, Besterman HS, Bloom SR 1986 Release of Peptide YY (PYY) after resection of small bowel, colon or pancreas in man. Surgery (in press)

18. Euler AP, Byrne WJ, Cousins LM, Ament ME, Leake RO, Walsh JD 1977 Increased serum gastrin concentrations and gastric acid hyposecretion in the immediate newborn period. Gastroenterology 72:1271-1273

19. Lucas A, Aynsley-Green A, Bloom SR 1981 Gut hormones and the first meals Clin Sci 60:349-353

20. Ebers DW, Smith DI, Gibbs GE 1956 Gastric acidity on the first day of life. Paediatrics 18:800-802

21. Harries JT, Fraser AJ 1968 The acidity of the gastric contents of premature babies during the first fourteen days of life. Biol Neonate 12:186-193

22. Christie DL 1981 Development of gastric function during the first month of life. In: Lebenthal (ed). Textbook of Gastroenterology and Nutrition in Infancy, Raven Press, New York, pp 109-121

23. Rogers IM, Davidson DC, Lawrence J, Ardill J. Buchanan KD 1974 Neonatal secretion of gastrin and glucagon. Arch Dis Child 49:796-801

24. Lucas A. Adrian TE, Christofides ND. Bloom SR. Aynsley-Green A 1980 Plasma motilin, gastrin and enteroglucagon and feeding in the human newborn. Arch Dis Child 55:673-677 